\title{
POLIPROPILENO RECICLADO MODIFICADO COM PÓ DE MADEIRA EM SOLOS DO MUNICÍPIO DE MACAPÁ-AP*
}

\author{
Diuvanaia Dias ${ }^{1}$ \\ Johnny Gilberto Moraes Coelho' \\ Carmen Gilda Barroso Tavares Dias ${ }^{3}$
}

\section{Resumo}

No presente trabalho busca-se avaliar o comportamento do solo virgem e com os resíduos, compactado, uma alternativa para área de Construção Civil. O estudo tem o objetivo de avaliar o solo (classificado como solo laterítico); e solo composto de polipropileno reciclado (rPP) e pó de madeira (PM); caracterizando a forma física e mecânica de rPP/PM para aterro. Neste trabalho, investiga-se a influencia dessas adições no comportamento mecânico de camadas compactadas de solo, avaliando o efeito do teor de composto rPP/PM. As amostras de polipropileno reciclado (rPP), e serragem (PM), foram separadas cada uma em 10\%, 20\% e 30\%, e aquecidas juntas, após o aquecimento misturadas ao solo. Sendo classificado como solo de baixa compressibilidade (ML), caracterizando um silte argiloso. Segundo a classificação HBR, tem-se P200 < 35\%, LL > 40, IP < 10 e IG =0, assim o grupo de classificação pertence ao grupo A-2, subgrupos A-2-5. Os resultados de Índice de Suporte Califórnia (ISC) do solo em estudo foram de $41 \%$ para amostra de solo e $130 \%$ para amostra de solo mais compósito.

Palavras-chave: ISC; Pó de madeira; Polipropileno reciclado.

\section{RECYCLED POLYPROPYLENE MODIFIED WITH WOOD POWDER IN SOILS OF MACAPÁ CITY}

\begin{abstract}
In this paper seek to evaluate the behavior of the virgin soil and waste, compressed, an alternative to civil construction. The study aims to evaluate the soil (classified as laterite soil); and recycled polypropylene composite soil (rPP) and wood powder (PM); characterizing the physical and mechanical form of rPP/PM to landfill. This work investigates the influence of these additions on mechanical behavior of compacted soil layers, assessing the effect of rPP/PM compound content. Samples of recycled polypropylene (rPP) and sawdust (PM), were each separated by $10 \%$, $20 \%$ and $30 \%$, and heated together, after heating the mixed soil. It is classified as low compressibility soil (ML), featuring a clayey silt. According HBR classification, it has been $\mathrm{P} 200<35 \%$, LL $>40 \mathrm{IP}<10$ and $\mathrm{LI}=0$, so the rating group belongs to the group A-2, A-2-5 subgroups. The results California Bearing Ratio (CBR) from the soil in this study were $41 \%$ for the soil sample, and $130 \%$ for more composite soil sample.
\end{abstract}

Keywords: CBR; Wood powder; Recycled polypropylene.

\footnotetext{
Tecnólogo em Construção de Edifícios, Instituto Federal do Amapá, Macapá, Amapá e Brasil. Engenharia Civil, Mestre, Professor, Instituto Federal do Amapá, Macapá, Amapá e Brasil.

Engenharia Química, Doutora, Professora, Programa de pós-graduação em Engenharia Mecânica, Universidade Federal do Amapá, Belém, Pará e Brasil.
} 


\section{INTRODUÇÃO}

Para Vargas a engenharia civil, como a grande maioria de suas obras em que são apoiadas sobre ou inferior da crosta terrestre, os materiais que formão essa última, sob tal ponto de vista, materiais de construção (1).

O aumento da produção mundial de plástico e a falta de programas de gestão adequada de resíduos, pós-consumo resultam no descarte inadequado e na sua disposição nos ambientes terrestres e aquáticos, causando inúmeros impactos ambientais e afetando, inclusive, saúde humana (2).

Esses resíduos poliméricos gerados pela sociedade representam um grande problema ambiental, pois podem demorar séculos para se degradar e ocupam grande parte de volume dos aterros sanitários, interferindo de forma negativa nos processos de estabilização biológica. Além disso, quando descartados em lugares inadequados, causam um impacto ainda maior ao meio ambiente.

O polipropileno (rPP) foi o polímero utilizado no presente trabalho, é um polímero termoplástico de estrutura semicristalina do grupo das poliolefinas, de massa molar entre 80.000 e $500.000 \mathrm{~g} / \mathrm{mol}$, com densidade em torno de 0,90 g/cm3 e índice de refração igual a 1,49 (3).

Outro aspecto muito relevante para o desenvolvimento deste trabalho é o aproveitamento do potencial brasileiro de resíduos de madeira. Nessa perspectiva fez reaproveitamento da serragem, gerados diariamente nas serrarias,sendo um material leve e fácil de se trabalhar.

Esses materiais podem apresentar bom desempenho mecânico, são facilmente moldáveis por extrusão ou injeção, têm a aparência de madeira (madeira plástica) e contribui para reduzir o impacto ambiental causado pela produção e descarte de bens de consumo (3).

O pó de madeira (PM) na forma de serragem é um material pouco utilizado, no Estado de Macapá, sendo descartado no ambiente ou utilizado por empresas de fabricação de tijolos. Assim podendo ser reaproveitado devido à madeira ter a função de aumentar a rigidez do compósito. No presente trabalho, não se tem um tipo de madeira especifica já que o PM foi extraindo de uma serraria, onde ocorre a moagem das madeiras através da fabricação de moveis. Com esse intuito, diversas pesquisas foram realizadas no Laboratório de Edificações do Instituto Federal do Amapá visando empregar o polipropileno reciclado (rPP) e o pó da serragem (PM) no solo. Sendo a predominância do solo da região em estudo, um latossolo de cor avermelhada.

Este trabalho será dividido em partes, de acordo com as pesquisas realizadas, iniciando com o tipo de solo e suas características. Essas características foram classificadas de acordo com os ensaios de Granulometria, Limite de Liquidez, Plasticidade, Compactação, expansão e Índice de suporte Califórnia (ISC), desta forma serão realizados ensaios do solo virgem e com os resíduos. Foi analisado o comportamento do material formado de solo silte argiloso, com polipropileno reciclado reforçado com $\mathrm{PM}$.

O principal objetivo desta pesquisa foi verificar as características físicas e o comportamento mecânico do solo na fabricação do compósito com as adições do Polipropileno (rPP) e da serragem (PM).

Tendo como objetivo específico submeter a tensões, suporte do solo, e verificar assim sua viabilidade na engenharia civil. Avaliando esses comportamentos, estabelecendo padrões de acordo com as normas técnicas e a revisão bibliográfica a respeito do assunto, e assim avaliar mecanicamente o solo laterítico em estudo. 
A Introdução deve conter uma breve apresentação do trabalho, contendo os objetivos e a revisão da literatura.

\section{MATERIAIS E MÉTODOS}

Os materiais utilizados para a confecção do compósito foram Solo, Polipropileno (rPP) e a serragem(PM).

O Solo em estudo é proveniente de uma jazida localizada no bairro do Brasil Novo, localizado na Rodovia BR 156, km³, em Macapá, Amapá (Figura 1).

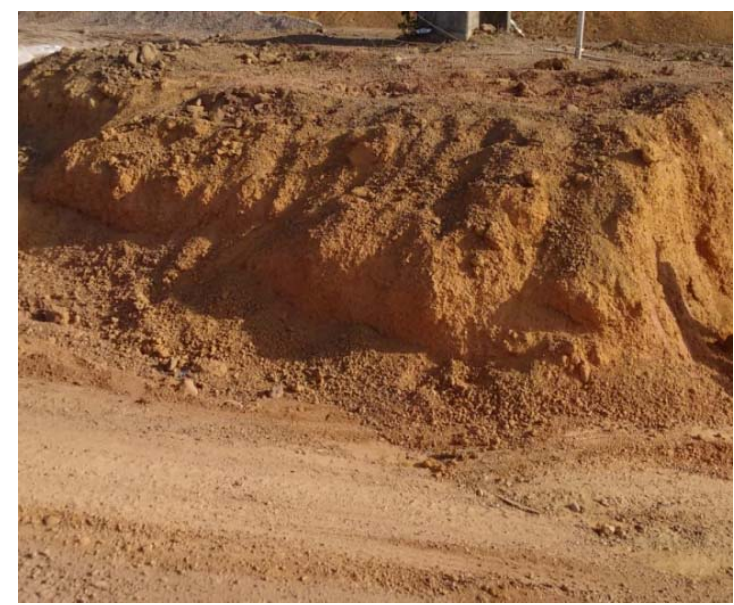

Figura 1. Local da amostra coletada.

Para esses ensaios utilizamos como referência a norma ABNT (4) para preparação das amostras. Destorroar o solo com o auxilio do almofariz e mão de gral recoberta de borracha, passando-o na perneira $4,8 \mathrm{~mm}$, desprezando o material retido. $O$ passante será utilizado para as caracterizações massa especifica dos grãos, determinação de seus índices físicos e de compactação.

O solo é um material constituído por um conjunto de partículas sólidas, deixando entre si vazios que poderão estar parcial ou totalmente preenchidos pela água (5).

Os índices Físicos que serão apresentados desempenham um importante papel no estudo das propriedades dos solos, uma vez que estas dependem de uma fase sobre as outras para interação das partículas e gerar um bom compósito.

Foram examinadas algumas propriedades do material solo como ele é encontrado, na natureza para a sua identificação e classificação como material de Construção como no seu estado natural, classificando-o como solo laterítico.

A Tabela 1 apresenta as seguintes características do solo laterítico estudado neste trabalho.

Tabela 1. Características e Índices físicos do solo estudado.

\begin{tabular}{ll}
\hline Índices Físicos & Valores \\
\hline $\mathrm{Y}=$ peso específico real $\left(\mathrm{g} / \mathrm{cm}^{3}\right)$ & 2,51 \\
\hline $\begin{array}{l}\mathrm{Yd}=\text { peso específico aparente seco } \\
\left(\mathrm{g} / \mathrm{cm}^{3}\right)\end{array}$ & 2,48 \\
\hline $\begin{array}{l}\mathrm{Ys}=\text { peso específico solo seco } \\
\left(\mathrm{g} / \mathrm{cm}^{3}\right)\end{array}$ & 1,11 \\
\hline $\mathrm{S}=\mathrm{grau}$ de saturação $(\%)$ & 60 \\
\hline $\mathrm{N}=$ porosidade & 0,36 \\
\hline $\mathrm{E}=$ índice de vazios & 0,55 \\
\hline $\begin{array}{l}\text { Ysat }=\text { peso específico solo saturado } \\
\left(\mathrm{g} / \mathrm{cm}^{3}\right)\end{array}$ & 1,97 \\
\hline
\end{tabular}


O polipropileno utilizado no estudo foi de garrafas de água mineral (Figura 2). De acordo com o fabricante, este possui um índice de fluidez médio, indicado para moldagem por injeção e extrusão de fibras e é um produto atóxico, com excelente processabilidade, boa estabilidade do fundido e baixa transferência de sabor e odor (3).

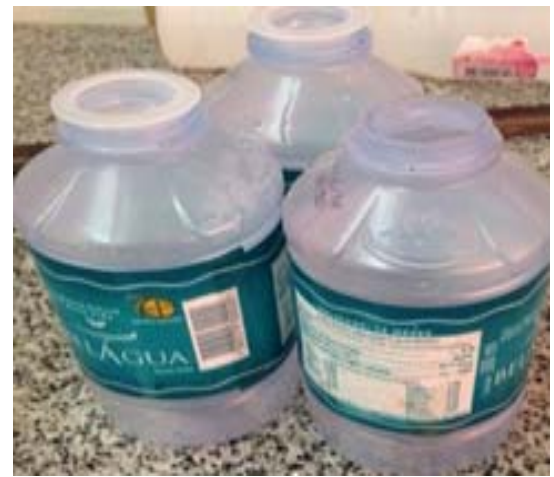

Figura 2. Amostra Garrafa de Polipropileno reciclado (rPP)

O Polipropileno (rPP) passou por um processo de triagem, onde esse processo se dar por uma separação de um material,onde o próprio passou por uma seleção. Esse material foi cortado em pequenos pedaços aproximadamente a $0,05 \mathrm{~cm}$ e separado em porcentagens de $10 \%, 20 \%$ e $30 \%$ em relação ao volume total de solo usado neste experimento (Figura 3).

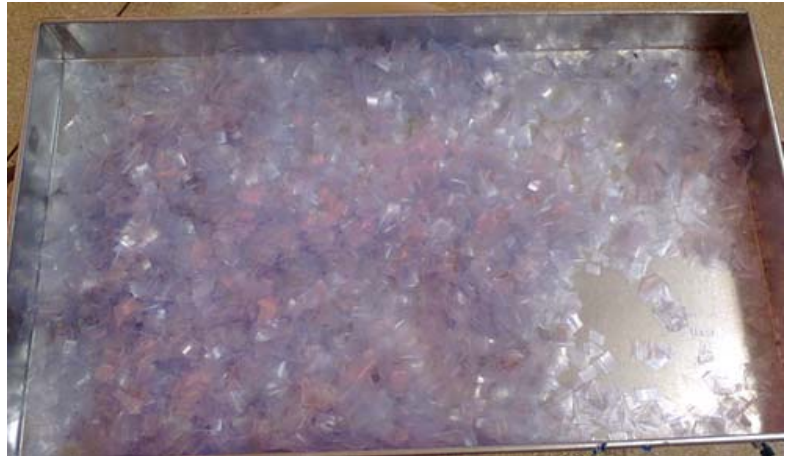

Figura 3. Amostra Garrafa de Polipropileno reciclado (rPP).

O rPP utilizado neste trabalho apresenta as seguintes características, de acordo com a classificação da Norma DNER (6), pelo do método do Picnômetro, medindo a massa contida recipiente levando-o a estufa, a densidade obitida foi de $0,71 \mathrm{~g} / \mathrm{cm}^{3}$.

Pó de madeira utilizado no estudo conhecido como serragem, cuja origem foi através do processo de moagem, pelas serrarias. Para este trabalho, utilizaram-se PM com o tamanho das partículas passante na peneira de abertura da malha 0,850 (índice mesh, peneira Tyler), secado naturalmente separado em 10\%, 20\% e 30\%. Sua classificação foi através do método do Picnômetro, medindo a massa contida recipiente levando-o a estufa, onde a densidade do pó de madeira é $1,33 \mathrm{~g} / \mathrm{cm}^{3}$.

Depois esses polímeros já cortados em pequenas partículas passaram por uma chapa para que venham ser misturado á serragem, e em seguida ao solo, tornandoo mais resistente e com que o composto rPP/PM ocupe mais espaços, preenchendo os vazios que nele existente. 
Os materiais (rPP/PM) serão misturados no processo de aglutinação. Em uma chapa de aquecimento com o tempo diretamente proporcional à quantidade de materiais, no qual a média de tempo foi estimada em 15 á 20 minutos (figura 4).

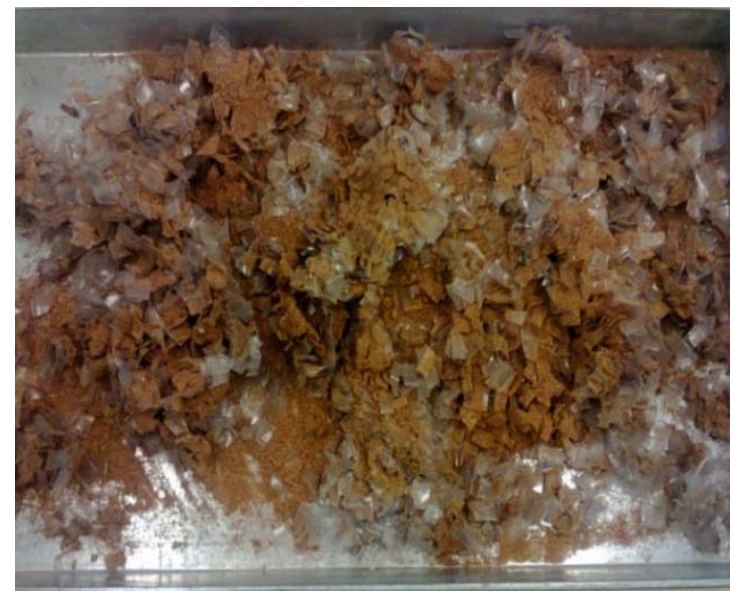

Figura 4. Amostra (rPP/PM), após passarem pelo aquecimento.

\section{RESULTADOS E DISCUSSÃO}

Depois do processamento dos materiais serão misturados ao solo para a classificação do compósito de acordo com a Norma DNER (6), pelo do método do Picnômetro, onde a densidade do composto rPP/PM é $1,34 \mathrm{~g} / \mathrm{cm}^{3}$.

O ensaio granulométrico é um método de análise que visa classificar as partículas de uma amostra pelos respectivos tamanhos e medir as frações correspondentes as porcentagens retidas em cada perneira (peneiras da ASTM), cujas dimensões são padronizadas. A classificação de um agregado é determinada comparando sua composição granulométrica com as faixas granulométricas especificadas em normas. A curva granulométrica nos permite ter uma visibilidade melhor dos tamanhos dos agregados, com isso reduzir vazios e melhorar a interface pasta nos agregado.

Segundo Caputo, as dimensões das suas partículas e dentro de determinados limites convencionais, as "frações constituintes" dos solos recebem designações próprias que se identificam com as acepções usuais dos termos (5). Essas frações, de acordo com a escala granulométrica brasileira (ABNT), são pedregulho conjunto de partículas cujas dimensões (diâmetros equivalentes) estão compreendidas entre 76 e 4,8mm; areia, entre 4,8 e 0,05 mm; silte, entre 0,05 e 0,005 mm; argila, inferiores a $0,005 \mathrm{~mm}$.

Composição da Analise Granulométrica de solo laterítico representando as porcentagens de cada abertura das peneiras (Tabela 2).

Tabela 2. Composição granulométrica do solo laterítico.

\begin{tabular}{ccccccc}
\hline $\begin{array}{c}\text { Peneira } \\
(\mathrm{MESH})\end{array}$ & $\begin{array}{c}\text { Abertura } \\
(\mathrm{mm})\end{array}$ & $\begin{array}{c}\text { Massa } \\
\text { Retida }(\mathrm{g})\end{array}$ & $\begin{array}{c}\text { Fração } \\
\text { Retida }(\Delta \mathrm{X})\end{array}$ & $\begin{array}{c}\text { Porcentagem } \\
\text { Retida }(\Delta \mathrm{X} \%)\end{array}$ & $\begin{array}{c}\text { Fração } \\
\text { Passante }(\mathrm{X})\end{array}$ & $\begin{array}{c}\text { Porcentagem } \\
\text { Passante }(\mathrm{X} \%)\end{array}$ \\
\hline 4 & 4,75 & 500 & 0,5016 & 50,15 & 0,4984 & 49,84 \\
\hline 10 & 2,00 & 178,05 & 0,1786 & 17,86 & 0,3198 & 31,98 \\
\hline 20 & 0,85 & 71,72 & 0,0719 & 7,194 & 0,2479 & 27,78 \\
\hline 40 & 0,425 & 41,42 & 0,0415 & 4,155 & 0,2063 & 20,63 \\
\hline 60 & 0,25 & 50,52 & 0,0507 & 5,067 & 0,1557 & 15,56 \\
\hline 100 & 0,125 & 61,6 & 0,0618 & 6,179 & 0,0939 & 9,386 \\
\hline 200 & 0,075 & 80,37 & 0,0806 & 8,062 & 0,0132 & 1,324 \\
\hline FUNDO & & 13,2 & 0,0132 & 1,3241 & 0,0000 & 0,0000 \\
\hline$\Sigma$ & & 996,88 & 1,0000 & 100,000 & & \\
\hline
\end{tabular}


Composição da Analise Granulométrica do compósito representando as porcentagens de cada abertura das peneiras (Tabela 3).

Tabela 3. Composição granulométrica do compósito.

\begin{tabular}{ccccccc}
\hline $\begin{array}{c}\text { Peneira } \\
(\mathrm{MESH})\end{array}$ & $\begin{array}{c}\text { Abertura } \\
(\mathrm{mm})\end{array}$ & $\begin{array}{c}\text { Massa } \\
\text { Retida }(\mathrm{g})\end{array}$ & $\begin{array}{c}\text { Fração } \\
\text { Retida }(\Delta \mathrm{X})\end{array}$ & $\begin{array}{c}\text { Porcentagem } \\
\text { Retida }(\Delta \mathrm{X} \%)\end{array}$ & $\begin{array}{c}\text { Fração } \\
\text { Passante }(\mathrm{X})\end{array}$ & $\begin{array}{c}\text { Porcentagem } \\
\text { Passante }(\mathrm{X} \%)\end{array}$ \\
\hline 4 & 4,75 & 143,57 & 0,1431 & 14,3148 & 0,8569 & 85,6852 \\
\hline 10 & 2,00 & 288,4 & 0,2876 & 28,5752 & 0,5693 & 56,9301 \\
\hline 20 & 0,85 & 170,9 & 0,1704 & 17,0397 & 0,3989 & 39,8903 \\
\hline 40 & 0,425 & 126,9 & 0,1265 & 12,6527 & 0,2724 & 27,2376 \\
\hline 60 & 0,25 & 100,75 & 0,1005 & 10,0454 & 0,1719 & 17,1923 \\
\hline 100 & 0,125 & 76,77 & 0,0765 & 7,6544 & 0,0954 & 9,5379 \\
\hline 200 & 0,075 & 84,82 & 0,0846 & 8,4571 & 0,0108 & 1,0808 \\
\hline FUNDO & 10,84 & 0,0108 & 1,0808 & 0.0000 & 0,0000 \\
\hline$\Sigma$ & 1002,95 & 1,0000 & 100,0000 & & \\
\hline
\end{tabular}

Analise granulométrica, ou seja, a determinação das dimensões das partículas do solo e das proporções relativas em que elas se encontram, é representada, graficamente pela curva granulométrica. Esta curva é traçada por pontos em um diagrama semi- logarítmico; no qual, sobre o eixo das ordenadas as porcentagens, em peso, de material que tem dimensão média menor que a dimensão considerada, onde se fez para solo laterítico (Figura 5) e solo laterítico com rPP/PM.

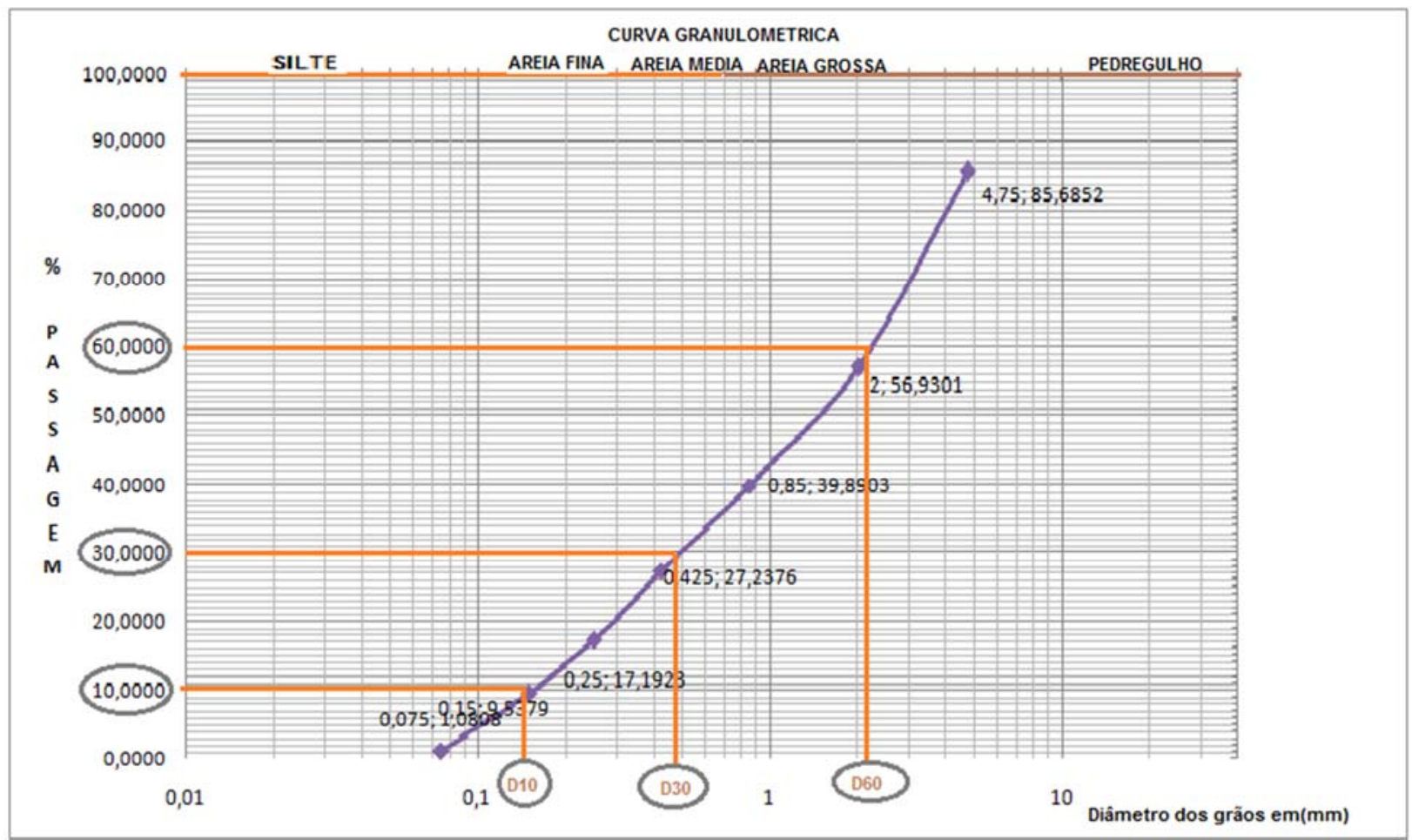

Figura 5. Acumulado retido e o acumulado passante do solo laterítico. 

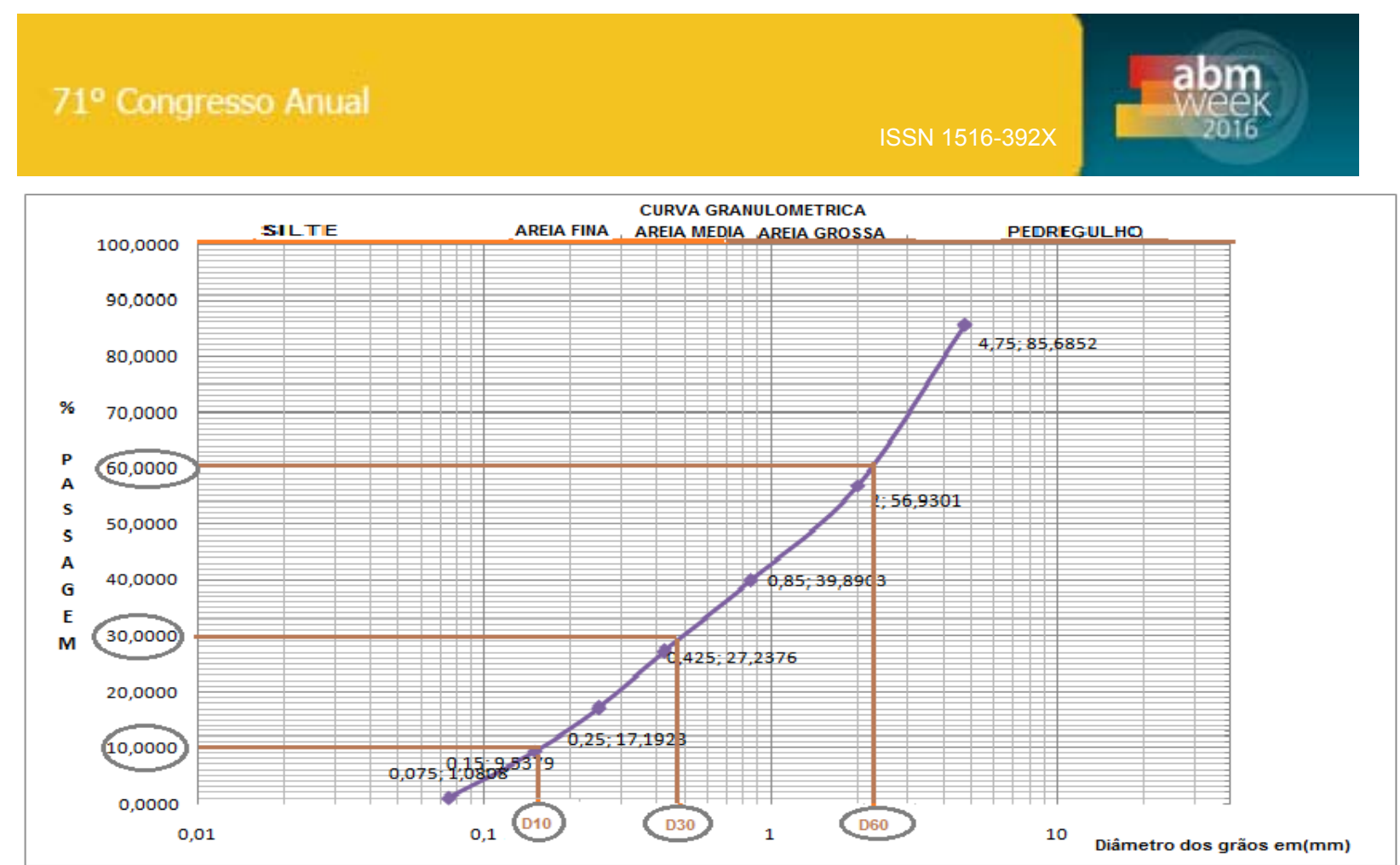

Figura 6. Acumulado retido e o acumulado passante do solo laterítico com rPP/PM.

A curva granulométrica por peneiramento (Figura 1) do solo laterítico apresentou $90 \%$ de seus grãos de diâmetros inferiores a $10 \mathrm{~mm} ; 60 \%$ de diâmetros inferiores a $2 \mathrm{~mm} ; 30 \%$ de diâmetros inferiores $0,5 \mathrm{~mm}$ e $10 \%$ diâmetros inferiores $0,2 \mathrm{~mm}$. Já curva granulométrica do compósito (Figura2) apresentou 90\% de seus grãos de diâmetros inferiores a $10 \mathrm{~mm} ; 60 \%$ de diâmetros inferiores a $2 \mathrm{~mm} ; 30 \%$ de diâmetros inferiores $0,5 \mathrm{~mm}$ e $10 \%$ diâmetros inferiores $0,2 \mathrm{~mm}$. Os dois materiais apresentaram grau de uniformidade $(U)$ de 20 e coeficiente de curvatura (CC) de 0,8 . De acordo com Caputo, é desuniforme pelo grau de $U>15$, tornando-o material pouco graduado (5).

O Limite de liquidez (LL) é a quantidade limite de umidade no solo, quando o mesmo muda do estado líquido para o estado plástico, ou seja, perde a sua capacidade de fluir (7).

A determinação do limite de liquidez (LL) é feita pelo aparelho de Casagrande, que consiste em um prato de latão, em forma de concha, sobre um suporte de ebonite; por meio de um excêntrico imprime-se ao prato, repetidamente, quedas de altura de $1 \mathrm{~cm}$ em e intensidade constante e um cinzel, onde com o mesmo será feito a ranhura.

A amostra promovida de material para o ensaio foi de aproximadamente $100 \mathrm{~g}$. Preparada de acordo com a Norma (4). Colocada em uma cápsula de porcelana e homogeneizada com acrescentamentos de água mexendo-a com a espátula metálica ate se obtiver uma pasta homogenia com consistência, colocando na concha em seguida divida-se a massa de solo em duas partes, passando o cinzel através da mesma, de maneira a abrir uma ranhura em sua parte central, o cinzel deve ser deslocado perpendicularmente à superfície da concha. Procedendo-se, por meio de acionamento da manivela, o golpeamento da concha contra a base do aparelho, tal que seja necessário 35 golpes para o fechamento da ranhura. Transferir, imediatamente, uma pequena quantidade do material de junto das bordas que se uniram para um recipiente adequado, levando-o para a estufa para a determinação da umidade. Transferir o restante da massa para a cápsula de porcelana. Lavar e enxugar a concha e o cinzel, adicionar água à amostra e homogeneizar durante pelo menos 3 minutos, amassando e revolvendo vigorosa e 
continuamente com auxilio da espátula, repetindo a mesma operação para os pontos seguintes.

Composições das Analises dos limites de liquidez do solo laterítico e solo compósito, representando os números de Golpes e Teores de umidade.

Com os resultados obtidos do limite de liquidez, constrói-se o gráfico no que podemos verificar e acoplar com os resultados do limite de plasticidade pra se obter o Índice de Plasticidade. O gráfico representa os pontos obtidos à linha de tendência do teor de umidade correspondente a 25 golpes, que é o limite de liquidez do solo laterítico (Figura 7) e do solo.

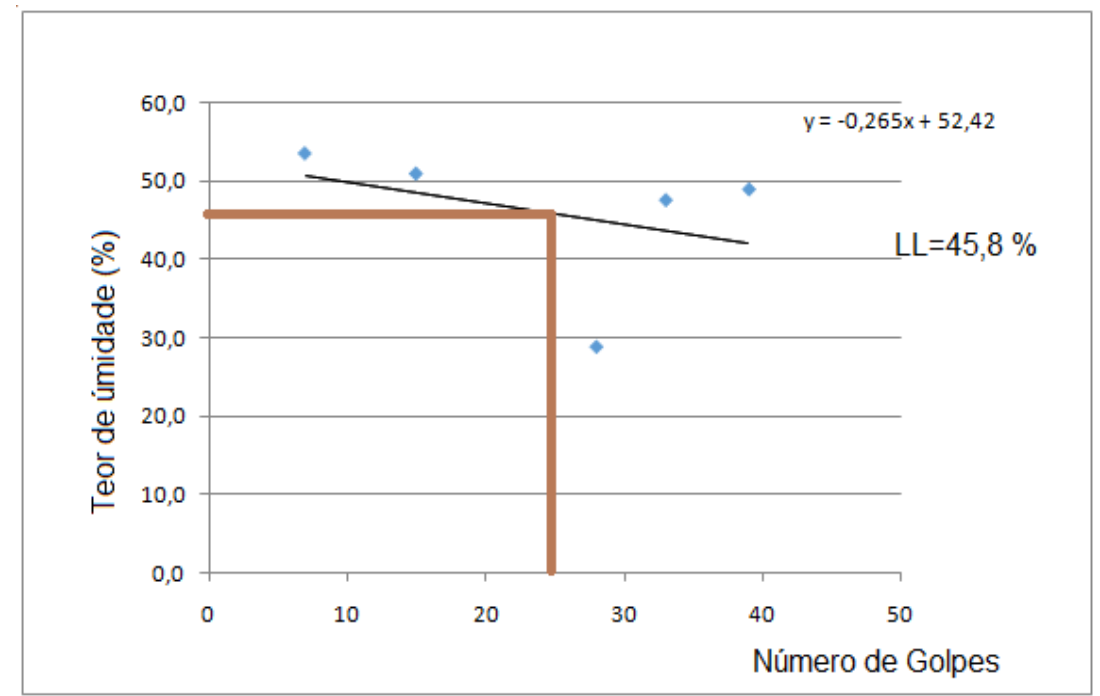

Figura 7. Gráfico Limite de plasticidade do solo laterítico segundo Casagrande.

A plasticidade é normalmente definida como uma propriedade dos solos, que consiste na maior ou menor capacidade de serem eles moldados, sob certas condições de umidade, sem variação de volume (5).

O limite de plasticidade (LP, é determinado pelo cálculo da porcentagem de umidade para a qual o solo começa a se fraturar quando ao se tenta moldar, com ele, um cilindro de $3 \mathrm{~mm}$ de diâmetro e cerca de 10 em de comprimento.

O Limite de plasticidade é o teor de umidade abaixo do qual o solo passa do estado plástico para o estado semi-sólido, ou seja, ele perde a capacidade de ser moldado e passa a ficar quebradiço (7).

Com uma pequena quantidade de massa (solo), realiza-se uma pequena bola com aproximadamente $10 \mathrm{~g}$, que será rolada sobre uma placa de vidro (esmerilhada) com pressão suficiente da mão, de modo formar um cilindro. Quando este atingir a $3 \mathrm{~mm}$ (verificado com o cilindro de comparação) e sem se fragmentar, ele deve ser amassado e tirado uma pequena amostra para o teor de umidade conforme a norma (8) e o restante do material é reutilizado a continuação do ensaio, que consiste em procede-se como anteriormente. Para o compósito foi retirado as partículas maiores do rPP, permanecendo maior quantidade de solo e serragem (PM) para a moldagem do cilindro.

Composições dos ensaios de limite de plasticidade do solo laterítico e solo compósito. (vê tabela 4 e 5). 
Tabela 4. Limite de Plasticidade do solo laterítico.

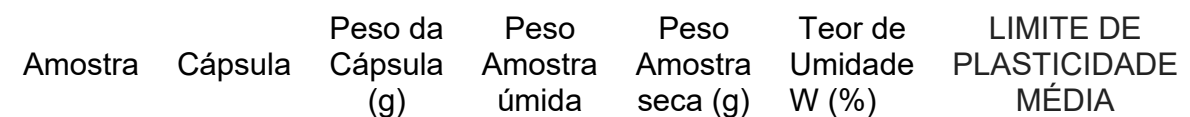

(g) úmida seca $(\mathrm{g}) \quad \mathrm{W}(\%) \quad$ MÉDIA

\begin{tabular}{cccccc}
\hline $1^{\mathrm{a}}$ & 6 & 15,82 & 0,94 & 0,68 & 38,23 \\
\hline $2^{\mathrm{a}}$ & 15 & 15,10 & 0,83 & 0,52 & 43,10 \\
\hline $3^{\mathrm{a}}$ & 9 & 15,42 & 0,71 & 0,58 & 36,53 \\
\hline $4^{\mathrm{a}}$ & 2 & 6,39 & 0,33 & 0,27 & 22,22 \\
\hline $5^{\mathrm{a}}$ & 16 & 5,94 & 6,62 & 6,42 & 3,11 \\
\hline
\end{tabular}

Tabela 5. Limite de Plasticidade do compósito.

\begin{tabular}{ccccccc} 
Amostra & Cápsula & $\begin{array}{c}\text { Peso da } \\
\text { Cápsula } \\
(\mathrm{g})\end{array}$ & $\begin{array}{c}\text { Peso } \\
\text { Amostra } \\
\text { úmida } \\
(\mathrm{g})\end{array}$ & $\begin{array}{c}\text { Peso } \\
\text { Amostra } \\
\text { seca }(\mathrm{g})\end{array}$ & $\begin{array}{c}\text { Teor de } \\
\text { Umidade } \\
\mathrm{W}(\%)\end{array}$ & $\begin{array}{c}\text { LIMITE DE } \\
\text { PLASTICIDADE } \\
\text { MÉDIA } \\
(\%)\end{array}$ \\
\hline $1^{\mathrm{a}}$ & 1 & 5,5 & 3,03 & 2,22 & 36,48 & \\
\hline $2^{\mathrm{a}}$ & 2 & 6,37 & 3,1 & 2,18 & 42,20 \\
\hline $3^{\mathrm{a}}$ & 3 & 5,92 & 2,55 & 1,84 & 38,58 & \multirow{2}{*}{39,53} \\
\hline $4^{\mathrm{a}}$ & 4 & 5,7 & 3,1 & 2,24 & 38,39 \\
\hline $5^{\mathrm{a}}$ & 5 & 6,47 & 3,38 & 2,43 & 39,09 & \\
\hline $6^{\mathrm{a}}$ & 6 & 5,89 & 3,68 & 2,64 & 39,39 & \\
\hline
\end{tabular}

De acordo com os resultados de LL e IP, ambos foram classificados como solo fracamente plásticos $1<\mathbb{I P}<7$ e um Silte Inorgânico de mediana compressibilidade (Tabela 6).

Tabela 6. Classificação do solo e material compósito em estudo.

\begin{tabular}{ccccccc}
\hline Amostra & Cápsula & $\begin{array}{c}\text { Peso da } \\
\text { Cápsula } \\
(\mathrm{g})\end{array}$ & $\begin{array}{c}\text { Peso } \\
\text { Amostra } \\
\text { úmida } \\
(\mathrm{g})\end{array}$ & $\begin{array}{c}\text { Peso } \\
\text { Amostra } \\
\text { seca }(\mathrm{g})\end{array}$ & $\begin{array}{c}\text { Teor de } \\
\text { Umidade } \\
\mathrm{W}(\%)\end{array}$ & $\begin{array}{c}\text { LIMITE DE } \\
\text { PLASTICIDADE } \\
\text { MÉDIA } \\
(\%)\end{array}$ \\
\hline $1^{\mathrm{a}}$ & 1 & 5,5 & 3,03 & 2,22 & 36,48 & \\
\hline $2^{\mathrm{a}}$ & 2 & 6,37 & 3,1 & 2,18 & 42,20 & \\
\hline $3^{\mathrm{a}}$ & 3 & 5,92 & 2,55 & 1,84 & 38,58 & \multirow{2}{*}{39,53} \\
\hline $4^{\mathrm{a}}$ & 4 & 5,7 & 3,1 & 2,24 & 38,39 & \\
\hline $5^{\mathrm{a}}$ & 5 & 6,47 & 3,38 & 2,43 & 39,09 & \\
\hline $6^{\mathrm{a}}$ & 6 & 5,89 & 3,68 & 2,64 & 39,39 & \\
\hline
\end{tabular}

De acordo com os resultados de LL e IP, ambos foram classificados como solo fracamente plásticos $1<\mathbb{I P}<7$ e um Silte Inorgânico de mediana compressibilidade (Tabela 7). 
Tabela 7. Classificação do solo e material compósito em estudo.

\begin{tabular}{|c|c|c|c|}
\hline Ensaios & $1^{\text {a }}$ Amostra (solo) & \multicolumn{2}{|c|}{$2^{\mathrm{a}}$ Amostra (compósito) } \\
\hline $\mathrm{LL}$ & \multicolumn{2}{|l|}{45,8} & 44,3 \\
\hline LP & 42,2 & \multicolumn{2}{|r|}{39,5} \\
\hline IP & 3,6 & \multicolumn{2}{|r|}{4,75} \\
\hline Granulométria & Ver Tabela 2 & \multicolumn{2}{|r|}{ Ver Tabela 3} \\
\hline & Classificação geral & Tipos principais & Símbolos \\
\hline UNIFICADO (U.S.C.) & $\begin{array}{c}\text { SOLOS FINOS } \\
\text { (Mais que } 50 \% \text { passando na \# } \\
200 \text { ) }\end{array}$ & $\begin{array}{l}\text { Solos Siltosos ou } \\
\text { argilosos }\end{array}$ & $\begin{array}{c}\text { Solos de baixa } \\
\text { compressibilidade ML, CL e } \\
\text { OL }\end{array}$ \\
\hline \multirow[t]{2}{*}{$\mathrm{HRB}-\mathrm{AASHO}$} & $\begin{array}{l}\text { Solos Granulares } \\
<\text { P200<35\% ) }\end{array}$ & Tipos de materiais & Classificação como subleito \\
\hline & A-2 (A-2-5) & $\begin{array}{l}\text { Pedregulhos e areias } \\
\text { siltosas ou argilosas }\end{array}$ & Excelente ou bom \\
\hline
\end{tabular}

No sistema SUCS, o solo é classificado como solo de baixa compressibilidade (ML), caracterizando um silte argiloso. Segundo a classificação HBR, tem-se P200 < 35\%, $\mathrm{LL}>40$, IP $<10$ e IG =0, assim o grupo de classificação pertence ao grupo A-2, subgrupos A-2-5. Assim o tipo de solo é, segundo as classificações, um silte argiloso, comum em subleito para pavimentos, considerado excelente para aplicação em engenharia, apresentando a mesma classificação do solo compósito.

Entende-se por compactação de um solo, o processo manual ou mecânico que visa reduzir o volume de seus vazios e, assim, aumentar sua resistência, tornando-o mais estável a umidade ótima (5).

Esse método tem com objetivo de melhorar as características no processo de eliminar vazios, aumentar a resistência e permeabilidade do solo por uma aplicação de energia exercida com um soquete em um cilindro com certa altura de queda.

As energias de compactação são especificadas na Norma NBR (9), como; normal, intermediaria e modificada.

$\mathrm{Na}$ tabela seguir está descritas as características referente à energia do ensaio realizado (Tabela 8 ).

Tabela 8. Energia de compactação.

\begin{tabular}{|c|c|}
\hline $\begin{array}{c}\text { CARACTERÍSTICAS INERENTES } \\
\text { (Cilindro) }\end{array}$ & ENERGIA \\
\hline Altura Cilindro Grande $(30,5 \mathrm{~cm})$ & \multirow{6}{*}{ INTERMEDIÁRIA } \\
\hline Volume do Cilindro $\left(2090 \mathrm{~cm}^{3}\right)$ & \\
\hline Soquete Grande $(4536 \mathrm{~g})$ & \\
\hline Número de camadas (5 camadas) & \\
\hline Número de golpes por camada (26) & \\
\hline Altura do disco espaçador $(63.5 \mathrm{~mm})$ & \\
\hline
\end{tabular}

Para a determinação da expansão do material é feita moldando-se um corpo de prova, com a umidade ótima (5). 
Segundo o engenheiro Valejos, o método de Índice de Suporte Califórnia (California Bearing Ratio) teve sua origem no estado da Califórnia, quando foi introduzido pelo engenheiro O. J. Porter em 1939 (10).

Para se obter o índice de suporte Califórnia (11), ou seja, a resistência a penetração de solos em laboratório utilizando amostras deformadas, a amostra de solo e composto é levada a carregamentos variáveis de acordo com o tempo e deve ser feito, após quarto dias de imersão do corpo-de-prova, ensaio de expansão (figura 8).

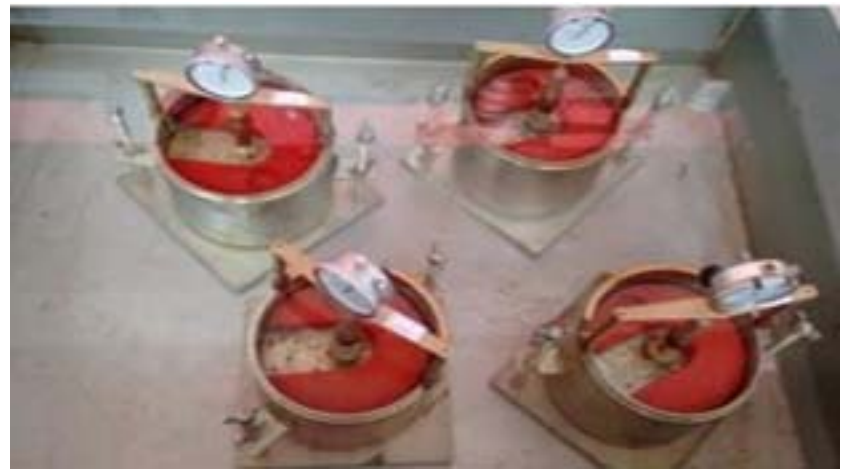

Figura 8. Ensaio de expansão do solo laterítico e compósito.

A preparação da mostra segue de acordo com a norma (11) para a caracterização do material passante na perneira $4,8 \mathrm{~mm}$.

Adiciona-se o volume de água calculado à amostra representativa do solo, procedendo-se a uma homogeneização adequada conforme as Figuras (9).
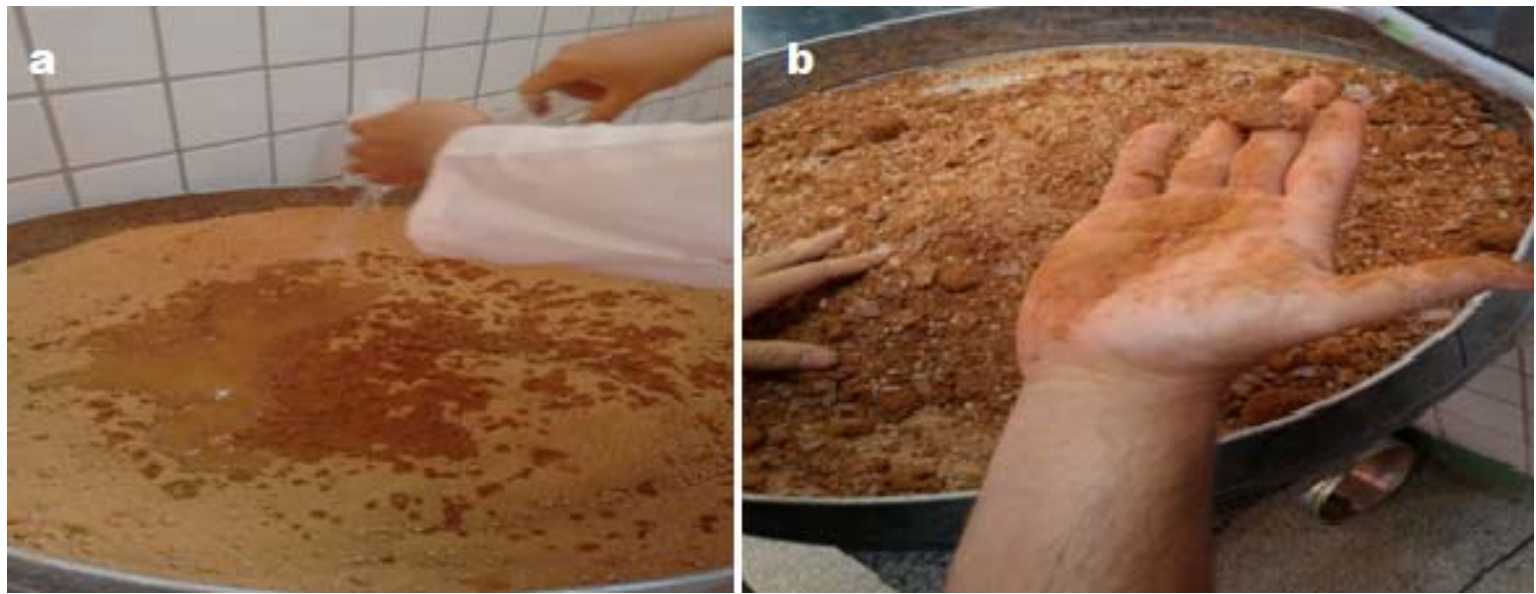

Figura 9. Ensaio de expansão do solo laterítico (a) e compósito (b).

\section{RESULTADOS E DISCUSSÃO}

Esse ensaio consiste em um cilindro sendo compactado em uma energia mencionada anteriormente. Tem-se os resultados do solo laterítico (Figura 10) e solo composto (Figura 11) de compactação e expansão na umidade ótima. 


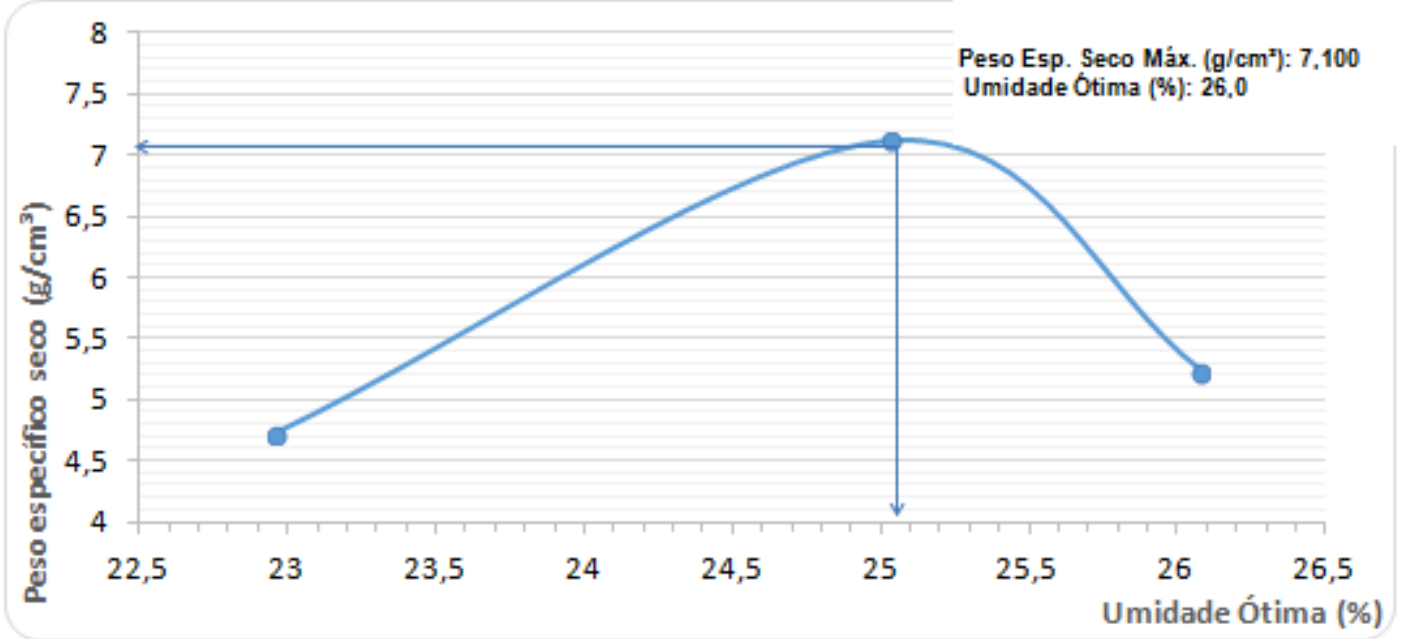

Figura 10. Compactação solo (umidade ótima).

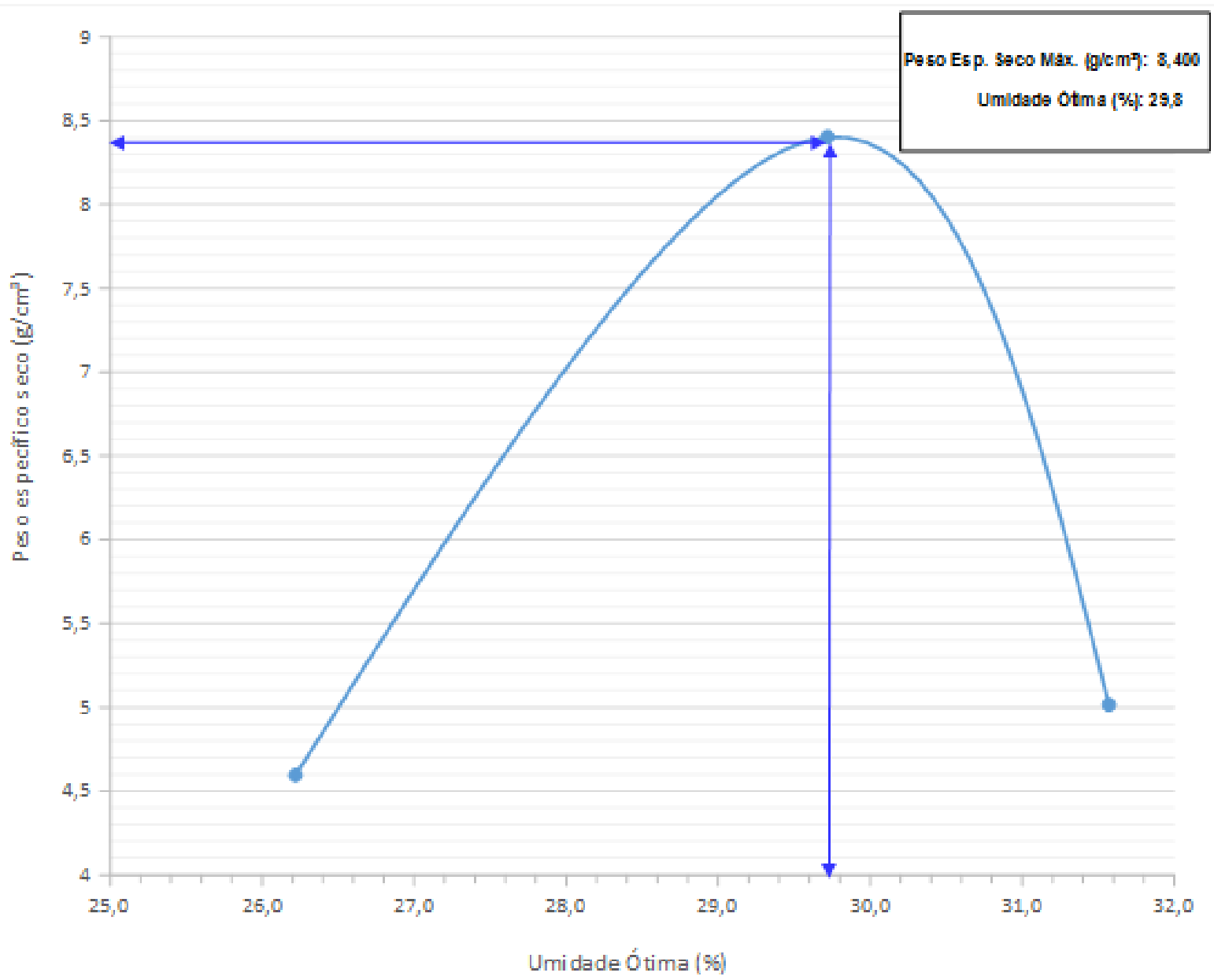

Figura 11. Compactação solo composto (umidade ótima).

A curva de Compactação foi obtida, marcando-se na abscissa os teores de umidade (h), e em ordenadas os pesos específicos secos correspondentes, Ys, as expanções obtidas para solo lateritico (Tabela 9) e para solo composto (Tabela 10) foram obtidas. 
Tabela 9. Resultados de expansão corrigida do solo laterítico.

\begin{tabular}{ccccc}
\hline $\mathrm{N}^{\mathrm{o}}$ do Cilindro & Leit.Inicial $(\mathrm{mm})$ & Leit.Final $(\mathrm{mm})$ & $\begin{array}{c}\text { Altura inicial do } \\
\text { corpo-de-prova } \\
(\mathrm{mm})\end{array}$ & Expansão (\%) \\
\hline 1 & 1,65 & 1,70 & 11,42 & 0,43 \\
\hline 2 & 0,23 & 0,85 & 11,42 & 5,42 \\
\hline 3 & 0,24 & 0,99 & 11,42 & 6,56 \\
\hline 4 & 0,34 & 0,72 & 11,42 & 3,32 \\
\hline
\end{tabular}

Tabela 10. Resultados de expansão corrigida do solo composto.

\begin{tabular}{ccccc}
\hline No do Cilindro & Leit.Inicial $(\mathrm{mm})$ & Leit.Final $(\mathrm{mm})$ & $\begin{array}{c}\text { Altura inicial do } \\
\text { corpo-de-prova } \\
(\mathrm{mm})\end{array}$ & Expansão (\%) \\
\hline 1 & 0,48 & 1,40 & 11,42 & 8,05 \\
\hline 2 & 0,43 & 0,24 & 11,42 & 0 \\
\hline 3 & 1,37 & 1,65 & 11,42 & 2,45 \\
\hline 4 & 0,44 & 0,26 & 11,42 & 0 \\
\hline
\end{tabular}

Assim se obteve o valor de umidade ótima, que corresponde à curva de compactação de $26 \%$, portanto o Índice de Suporte Califórnia (ISC) correspondente a umidade ótima para este solo laterítico é de $41 \%$ (correspondente a média de 12 amostras para solo laterítico); assim como o valor de umidade ótima, que corresponde à curva de compactação de 29,8\%, e Índice de Suporte Califórnia correspondente a umidade ótima para este solo composto de 180,21\% (correspondente a média de 12 amostras para solo composto).

\section{CONCLUSÃO}

$\mathrm{Na}$ avaliação dos resultados do solo laterítico, na $1^{\circ}$ amostra apresentou um baixo ISC de $11,05 \%$ e as demais amostras, apresentaram resultados significativos para 0 solo laterítico, na qual as demais amostras foram obtidos um ISC em média de $41 \%$ para uma umidade ótima aproximada a obtida no ensaio de compactação do solo laterítico, $26 \%$. Nas amostras do compósito apresentaram ISC mais elevado, sendo a $1^{\text {a }}$ amostra chegou a $130 \%$ com o teor de umidade $29,8 \%$, as demais amostras com média de $180,21 \%$. As mostras obtiveram a expansão do solo laterítico com a média de $4 \%$ e do compósito 3,5\%, ambas são consideradas aceitáveis na aplicação de subleitos, já para aterros apresentou uma boa expansão para o corpo do aterro, que de acordo com a norma (12) dever possuir ISC $\geq 2 \%$ e expansão $<4 \%$, ou o especificado em projeto.

\section{Agradecimentos}

Agradeço ao programa PIBIC/IFAP, e aos membros do Grupo de Pesquisa em Mecânica dos Solos e Asfalto do IFAP (GPMSA/IFAP).

\section{REFERÊNCIAS}

1 VARGAS, M. Introdução à mecânica dos solos. Ed. McGraw-Hill do Brasil. São Paulo, 1977.

2 OLIVEIRA, M. C. B. R. Gestão de resíduos plásticos pós-consumo: perspectivas para a reciclagem no brasil. Dissertação apresentada como requisito para obter o título de mestre em engenharia mecânica do Curso de Mestrado em Engenharia Mecânica da Universidade Federal do Paraná. Rio de Janeiro, 2012. 
3 TROMBETTA, E. Utilização de fibra natural de pinus (serragem) como reforço. Universidade Federal do Paraná, Curitiba, 2010.

4 ABNT - Associação Brasileira de Normas Técnicas. NBR 6457. Preparação amostras de solo - preparação para ensaios de compactação e ensaios de caracterização, 1986.

5 CAPUTO, H. P. Mecânica dos solos e suas aplicações, Fundamentos. Ed. LTC (ISBN 85-216-0271-5), 6a edição, vol.1, Rio de Janeiro, RJ, 1988.

6 DNER - DEPARTAMENTO NACIONAL DE ESTRADAS DE RODAGEM. ME 084/95: Agregado miúdo: Determinação da Densidade Real. Rio de Janeiro, 1995.

7 PUHL, R. H. Análise de melhoramento de solo do subleito com adição de cimento. Santa Rosa: Universidade Regional do Noroeste do Estado do Rio Grande do Sul, Unijuí, 2014.

8 ABNT - Associação Brasileira de Normas Técnicas. NBR 7180. Solo: Determinação do limite de plasticidade, 1984.

9 ABNT - Associação Brasileira de Normas Técnicas. NBR 7182. Solo:Ensaio de Compactação, 1986.

10 VALEJOS, C. V.; BAZAN, H. W.; LOYOLA, J. M.; \& CECCON, T. A. Cálculo de ensaios laboratoriais.Universidade Federal do Paraná, Curitiba, 2005.

11 ABNT - Associação Brasileira de Normas Técnicas. NBR 9895. Solo: Índice de Suporte Califórnia (CBR). Rio de Janeiro, 1987.

12 DERSA - DESENVOLVIMENTO RODOVIÁRIO S.A. ET-DE-Q00/004. Aterro Sobre Solos Compressíveis, 2006. 